\title{
Impact of Reference Dataset Selection on RCM Evaluation, Bias Correction, and Resulting Climate Change Signals of Precipitation
}

\author{
DAVID GAMPE, JOSEF SCHMID, AND RALF LUDWIG \\ Department of Geography, Ludwig-Maximilians-Universität, Munich, Germany
}

(Manuscript received 30 May 2018, in final form 31 March 2019)

\begin{abstract}
Gridded datasets of precipitation are of great importance to evaluate recent climate models and are frequently applied to select a subset of available models. As climate models are still prone to biases on the regional scale, gridded datasets are also essential to correct or adjust these biases. Various studies revealed considerable differences, that is, observational uncertainty, in the available gridded datasets of precipitation, especially over complex terrain. This study focuses on the impacts of observational uncertainty on the evaluation, selection, and bias correction of 15 regional climate model (RCM) simulations provided through the EURO-CORDEX initiative over the alpine Adige catchment located in northern Italy. Nine reference datasets originating from observations, reanalysis, and remote sensing are applied to evaluate the performance of RCMs and select a subset based on validity. These reference datasets are then applied to bias correct the RCM ensemble using a standard quantile mapping method, and the resulting changes in the projections are assessed. The presented results show a selection of similar RCMs, indicating that observational uncertainty is lower than model uncertainty. The influence of the choice of the reference dataset on bias correction is negligible for the climate change signals. Small differences in projected change signals can be attributed to model selection. As expected, the choice of the reference dataset strongly influences future projections of precipitation even more pronounced for the extremes. The findings of this study highlight the need to account for observational uncertainty for bias correction of RCM simulations for impact modeling studies.
\end{abstract}

\section{Introduction}

Climate models serve as a primary tool to project future climate and are thus frequently used to drive impact models to assess future changes on the environment. Regional climate models (RCMs) that dynamically downscale global climate models (GCMs) provide high-resolution projections and are therefore of particular interest over complex terrain (Torma et al. 2015). An ensemble of RCMs is provided through the Coordinated Regional Downscaling Experiment (CORDEX) at a common grid with a horizontal resolution of $0.11^{\circ}(\sim 12 \mathrm{~km}$, corresponding to the EUR-11 grid) over Europe (Jacob et al. 2014). Future scenarios are derived through representative concentration pathways (RCPs) that result in a range of the increased radiative forcing

Corresponding author: David Gampe, david.gampe@ googlemail.com of $2.6-8.5 \mathrm{~W} \mathrm{~m}^{-2}$ for the year 2100 (Van Vuuren et al. 2011).

Despite their increased resolution, RCM simulations are still prone to systematic errors, that is, model biases, when compared to regional observations (Christensen et al. 2008; Dosio 2016; Rajczak et al. 2016; Smiatek et al. 2016). A correction of these biases is usually inevitable and applied when climate models are used for climate change impact assessment studies (Piani et al. 2010; Ehret et al. 2012; Muerth et al. 2013). To cope with this issue, several adjustment or correction techniques have been established. Out of these, distribution-based approaches usually lead to more robust results (Chen et al. 2013a). Among those, quantile mapping (QM) is a widely applied technique to adjust climate model biases (Pierce et al. 2015; Addor et al. 2016) of precipitation, based on the distributions of historical datasets. In addition to the performance of QM compared to other approaches, the method is also transferable to other variables and thus favorable over other bias correction 
approaches (Themeß1 et al. 2011). After bias correction with QM the distribution of precipitation in the RCMs follows the distribution of the reference dataset applied for bias correction.

Additionally, it is often not feasible to consider the entire ensemble of available climate models in climate change impact assessment studies, mostly for computational reasons and the related difficulties to handle large datasets (Mendlik and Gobiet 2016). It is therefore necessary to define a subset of RCMs in a meaningful manner. Recent studies proposed a selection based on model independence (Mendlik and Gobiet 2016) or on a clustering approach based on climate change signals of various variables (Wilcke and Bärring 2016). Despite these statistical methods, model selection based on validity, that is, the capability of the climate models to reproduce historical precipitation or temperature, is still frequently applied (Pierce et al. 2009; Biemans et al. 2013; Kotlarski et al. 2017), possibly combined with analysis on model independence (Evans et al. 2014) or on climate change signals (Lutz et al. 2016).

Both bias correction and model selection represent typical steps in climate change impact assessment studies. However, at least if a selection based on validity is performed, both require the use of reference data for the desired variable to be corrected or applied for selection. For precipitation a great variety of datasets is available. These can either be station data or gridded products derived from observations (Haylock et al. 2008; Isotta et al. 2014; Schamm et al. 2016), constructed through reanalysis (Compo et al. 2011; Dee et al. 2011; Bosilovich et al. 2016; Landelius et al. 2016; Poli et al. 2016), or originate from remote sensing (Kummerow et al. 1998; Ashouri et al. 2015). Available gridded products of precipitation differ not only in their source, but also in spatial and temporal resolution as well as domain size. It is widely known that these precipitation datasets are also prone to errors, resulting from interpolation procedures or precipitation undercatch. Considerable differences exist for the general climatology (Palazzi et al. 2013; Isotta et al. 2015; Gampe and Ludwig 2017; Henn et al. 2018) and the representation of extremes (Herold et al. 2017).

Although the uncertainty related to gridded precipitation products is well known and widely acknowledged, the selection of the reference dataset is often an arbitrary choice and the role of observational uncertainty often excluded from the analysis. For bias correction, several studies were conducted to evaluate existing methods (Chen et al. 2013a; Lafon et al. 2013; RuizRamos et al. 2016); however, they rarely address the issue of reference or observational uncertainty (Iizumi et al. 2017) and mostly focus on a single reference dataset. For climate model selection and evaluation great effort was conducted in comparing different methods over the past years (e.g., Schaller et al. 2011; Zubler et al. 2016), but only recently Kotlarski et al. (2017) added to the debate in the application of various reference datasets for RCM selection based on a simple ranking scheme. The importance to consider observational uncertainty in precipitation for RCM evaluation over various areas over Europe was highlighted by Prein and Gobiet 2017.

The presented study adds to the debate and complements previous research by assessing the role of observational uncertainty in the typical procedure of RCM selection and bias correction performed in many impact assessment studies. These studies are typically carried out on the catchment scale as highlighted by Gampe and Ludwig (2017). The presented study is thus also carried out on the catchment scale. An alpine catchment serves as study site, and a total of nine gridded precipitation products from various sources are included in the analysis. The three main research questions addressed can be defined as follows:

- What is the impact of the choice of the reference dataset on bias detection and model selection?

- What is the impact of reference dataset selection on bias correction and resulting future projections for precipitation?

- How large is the contribution of the reference dataset selection to the overall uncertainty?

A simple ranking scheme based on validity is introduced, where the performance of each RCM as evaluated by each of the included reference datasets is assessed. The RCM ensemble is then bias corrected using each of the reference datasets, and the resulting climate change signals for the selected models are presented. To quantify the uncertainty introduced by the selection of the reference dataset, the relative contribution to the overall uncertainty is assessed by a variance decomposition approach.

\section{Study area and datasets}

\section{a. Study area}

This study is carried out over the catchment of the Adige River located in northern Italy. The catchment, presented in Fig. 1, covers an area of $12100 \mathrm{~km}^{2}$ ranging from the Southern Alps to the Adriatic Sea over a length of $409 \mathrm{~km}$ while passing three Italian provinces. About two-thirds of the catchment is located over complex 


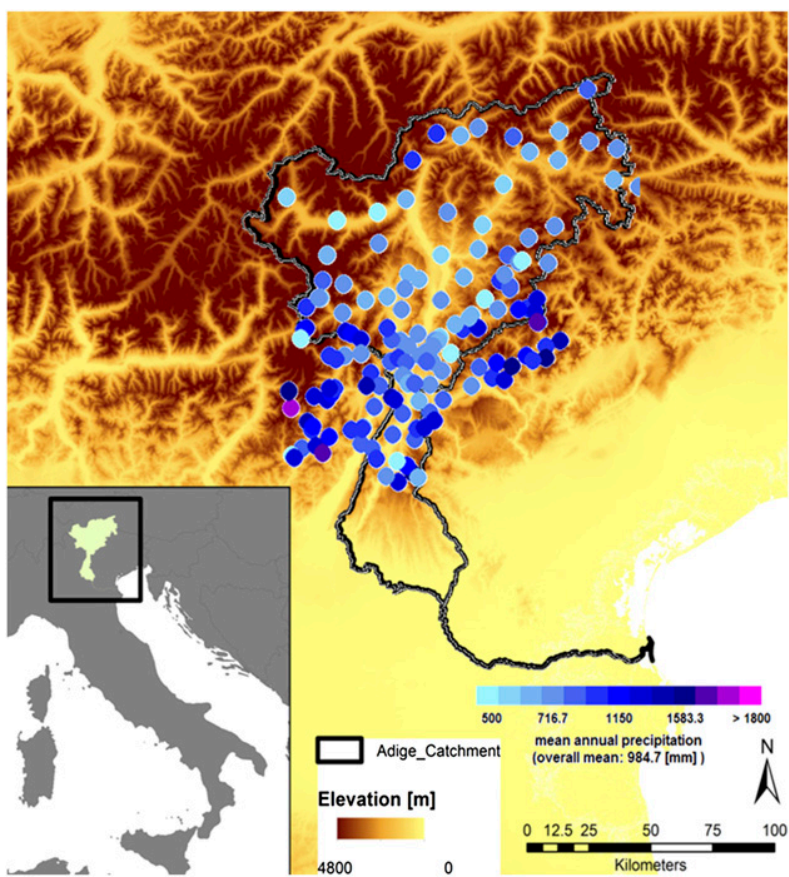

FIG. 1. The Adige catchment located in northern Italy. Circles show the precipitation gauges and their corresponding mean annual precipitation for the period 1989-2008.

terrain in the Alps, with elevations up to $3800 \mathrm{~m}$ MSL. The area is generally dominated by a humid climate with annual mean precipitation ranging from $500 \mathrm{~mm}$ over the inner-Alpine dry valleys, such as the Venosta valley (Frei and Schär 1998; Isotta et al. 2014), to $1600 \mathrm{~mm}$, with a strong peak in the summer months and comparatively dry winters (Chiogna et al. 2016). The hydrology of the Adige River is dominated by snow and glacier melting in the spring months and intense precipitation events in summer (Chiogna et al. 2016). The stream discharge serves for irrigation of intensive agriculture in summer and various touristic activities, especially in winter. Additionally, several reservoirs for power generation are located in the northern part of the catchment (Navarro-Ortega et al. 2015). The selection of the Adige catchment is also motivated by the availability of a large number of precipitation gauges (Gampe and Ludwig 2017) and a diverse set of available reference datasets.

\section{b. Gridded precipitation datasets}

At this point, a multitude of gridded datasets for precipitation are available around the globe. The selection is usually determined by the requirements regarding spatial and temporal resolution as well as the location of the study area. In this study, extremely coarse datasets $\left(>2.0^{\circ}\right.$ grid size $)$ were not included due to the comparatively small size of the catchment. Nevertheless, also coarse datasets with resolutions up to $125 \mathrm{~km}$ were selected for consistency reasons with the previous study (Gampe and Ludwig 2017). Despite the impact of spatial resolution on extreme precipitation, the coarse datasets included in this study frequently serve to drive impact models at the catchment scale, especially in data-scarce areas, and are therefore included in this study.

As the datasets served for bias correction of RCMs, the minimum temporal resolution was daily time steps. Monthly or seasonal datasets were hence also excluded from the analysis. Furthermore, to achieve a temporal coverage of at least 20 years, the period 1989-2008 was selected, corresponding to the maximum overlap of the high-resolution datasets. Therefore, datasets with a later starting data than 1 January 1989 or ending dates prior to 31 December 2008 were rejected. This led to a selection of the nine datasets summarized in Table 1 . These are briefly introduced in the following, while for detailed information the reader is referred to the corresponding references. An extensive comparison of these datasets was carried out over the study area in a previous study (Gampe and Ludwig 2017).

Four observational datasets derived from interpolation of precipitation gauge measurements are included in this study at spatial resolutions ranging from 1 to $\sim 100 \mathrm{~km}$. The highest-resolution dataset included is the local gridded precipitation dataset over the Adige at a $1-\mathrm{km}$ grid (ADG-1KGPR). This was derived from a relatively dense station network of over 150 stations in the catchment area, as presented in Fig. 1. A combination of bilinear interpolation with elevation dependent regression was applied to construct a 1-km high-resolution grid. Although the effective resolution is lower for some parts of the catchment, the dataset showed robust results over the covered period 1989-2008 (Gampe and Ludwig 2017). The second observational dataset included is the Alpine Gridded Dataset constructed within the EURO4m project (EURO4m-APGD). It was derived from numerous stations over the Alpine area and provides daily precipitation for the period 1971-2008 at a 5-km grid (Isotta et al. 2014). Additionally, the widely used E-OBS dataset (Haylock et al. 2008) available through the European Climate Assessment and Dataset (ECA\&D) was included in version 11.0. E-OBS provides daily precipitation information for the European domain at a $25-\mathrm{km}$ grid, starting in the year 1951, and is updated frequently. Quality-controlled stations with long data records are included in this dataset, resulting in a considerably lower station density, compared to the high-resolution grids mentioned, with approximately 
TABLE 1. Gridded precipitation datasets included in this study with their corresponding resolution, temporal coverage, source, and the reference publication. All datasets are available at daily time scale; the IDs correspond to the numbering in Figs. 3 and 4.

\begin{tabular}{|c|c|c|c|c|c|}
\hline ID & Dataset & Resolution & Temporal coverage & Type/source & Reference \\
\hline 1 & ADG-1KGPR & $1 \mathrm{~km}$ & 1989-2008 & Observations & Gampe and Ludwig (2017) \\
\hline 2 & EURO4m-APGD & $5 \mathrm{~km}$ & $1971-2008$ & Observations & Isotta et al. (2014) \\
\hline 3 & MESAN & $5 \mathrm{~km}$ & 1989-2010 & Downscaling/reanalysis & Landelius et al. (2016) \\
\hline 4 & E-OBS v. 11 & $25 \mathrm{~km}$ & 1950-2015 & Observations & Haylock et al. (2008) \\
\hline 5 & PERSIANN-CDR & $0.25^{\circ}(\sim 30 \mathrm{~km})$ & 1983-present & $\begin{array}{l}\text { Multisatellite (infrared), } \\
\text { corrected }\end{array}$ & Ashouri et al. (2015) \\
\hline 6 & MERRA-2 & $\begin{array}{r}0.5^{\circ} \text { latitude } \times 0.625^{\circ} \\
\text { longitude }(\sim 50 \mathrm{~km})\end{array}$ & 1980-present & Reanalysis & Bosilovich et al. (2016) \\
\hline 7 & ERA-Interim & $0.75^{\circ}(\sim 80 \mathrm{~km})$ & 1979-present & Reanalysis & Dee et al. (2011) \\
\hline 8 & ERA-20C & $125 \mathrm{~km}$ & $1900-2010$ & Reanalysis & Poli et al. (2016) \\
\hline 9 & GPCC-FDD v1.0 & $1.0^{\circ}(\sim 100 \mathrm{~km})$ & 1988-2013 & Observations & Schamm et al. (2016) \\
\hline
\end{tabular}

two stations per grid cell over the Alpine region (Isotta et al. 2015; Prein and Gobiet 2017). The coarsest observational dataset included is the Full Data Daily product of the Global Precipitation Climatology Center (GPCC-FDD; Schamm et al. 2016) of the German Weather Service (DWD). This dataset covers the period 1988-2013 and provides daily precipitation information on a $1^{\circ}$ grid with a station density similar to E-OBS.

In addition to the observational datasets, three reanalysis products and one downscaling of a reanalysis dataset are included ranging from a 5 - to $125-\mathrm{km}$ grid size. The first is the Modern-Era Retrospective Analysis for Research and Applications version 2 (MERRA-2) available through the National Aeronautics and Space Administration (NASA). The dataset provides precipitation information since 1980 on an $\sim 50$-km grid with ongoing updates and uses observed precipitation for the parameterization of the land surface scheme (Bosilovich et al. 2016). The two coarsest reanalysis products are available through the European Centre for MediumRange Weather Forecasts (ECMWF). The ERA-Interim provides global precipitation information at $\sim 80 \mathrm{~km}$ and assimilates various observational datasets in a 12-h cycle (Dee et al. 2011). The second ECMWF product is the reanalysis for the twentieth century (ERA-20C), which only assimilates surface pressure and marine wind observations (Hersbach et al. 2015; Poli et al. 2016). ERA-20C is available at an $\sim 125-\mathrm{km}$ grid and offers precipitation information since 1900 . The highestresolution product in this family is the Mesoscale Analysis (MESAN) that downscales the High Resolution Limited Area Model (HIRLAM) to a 5-km grid (Landelius et al. 2016). The HIRLAM reanalysis uses ERA-Interim as boundary conditions and assimilates observational data on a 22-km grid (Dahlgren et al. 2016). MESAN provides precipitation information for the period 1989-2010.
The last dataset included is the satellite-based Precipitation Estimation from Remotely Sensed Information Using Artificial Neural Networks (PERSIANN, Hsu et al. 1997) in the bias-corrected version PERSIANN-CDR. Geostationary satellite information of infrared brightness temperature is used in PERSIANN to derive precipitation patterns at $\sim 30-\mathrm{km}$ spatial resolution. PERSIANN-CDR corrects the precipitation amounts using monthly precipitation data from the Global Precipitation Climatology Project (GPCP) at $2.5^{\circ}$ while keeping the high resolution and the spatial patterns of the original PERSIANN and with data record since 1983 (Ashouri et al. 2015).

\section{c. Climate model data}

The climate models included in this study comprise 15 simulations provided through the Coordinated Regional Climate Downscaling Experiment over the European domain (EURO-CORDEX; Jacob et al. 2014). Table 2 gives an overview on the included GCM-RCM combinations with the responsible institute. As the higherresolution realizations of those RCMs at $0.11^{\circ}(12.5 \mathrm{~km})$ show improvements over the $0.44^{\circ}$ simulations (Prein et al. 2016), only the high-resolution simulations were applied. With the exception of the variance decomposition presented in section $3 \mathrm{c}$ and Fig. 9, only the simulations under RCP8.5 are considered, as the ambiguous climate change signals over the Adige catchment under RCP4.5 (Gampe et al. 2016) would complicate the interpretation of the results in this study, and RCP8.5 has become the most widely applied radiative forcing scenario. Therefore, with the mentioned exceptions, all results presented and conclusions drawn refer to RCP8.5 only.

All analyses and calculations presented in this study were carried out on a common grid. The EUR-11 grid was selected as target grid. Following previous studies, for example, Volosciuk et al. (2017), the bias correction 
TABLE 2. RCM ensemble of EURO-CORDEX simulations at 12-km resolution applied in this study under RCP4.5 and RCP8.5.

\begin{tabular}{ll}
\hline \multicolumn{1}{c}{$\begin{array}{c}\text { Regional climate model } \\
(\mathrm{RCM})\end{array}$} & \multicolumn{1}{c}{$\begin{array}{c}\text { General circulation model } \\
(\mathrm{GCM})\end{array}$} \\
\hline SMHI-RCA4 & CNRM-CM5 \\
& HadGEM2-ES \\
& EC-EARTH-r12 \\
& MPI-ESM-LR \\
& IPSL-CM5A-MR \\
DMI-HIRHAM5 & EC-EARTH-r3 \\
KNMI-RACMO22E & EC-EARTH-r12 \\
& HadGEM2-ES \\
CLMcom-CCLM4-8-17 & CNRM-CM5 \\
& HadGEM2-ES \\
& EC-EARTH-r12 \\
IPSL-INERIS-WRF331F & MPI-ESM-LR \\
MPI-CSC-REMO2009 (2 members $)$ & IPSL-CM5A-MR \\
\hline
\end{tabular}

was applied on the RCM grid. As it is desirable to keep the benefits of the higher-resolution RCMs, the reference datasets have been remapped to the EUR-11 grid by applying mass conserving aggregation or disaggregation. This approach clearly penalizes the coarserresolution datasets. Nevertheless, this study is not meant as an evaluation of the precipitation reference datasets, but rather focusing on the consequences for bias correction and model selection.

\section{Methods}

\section{a. Model selection}

Similar to previous studies (Pierce et al. 2009; Biemans et al. 2013; Kotlarski et al. 2017), model selection here is performed based on validity, that is, the capability of the RCMs to reproduce the historical period. A relatively simple scheme is presented to derive the performance of each RCM and a model ranking is performed. Although more sophisticated and complex approaches exist, the method presented here is sufficient for the purpose of this study, as the focus is not to elaborate a sophisticated ranking scheme and the presented metrics and ranking led to satisfactory results. In addition, it is crucial to mention that the ranking is dependent on the selected error measures and the overall focus of the study and hence somewhat subjective (Kotlarski et al. 2017). The model selection is based on uncorrected RCM data from the presented model ensemble. The following selection procedure is calculated based on each of the nine reference datasets.

To assess the performance of the RCMs and to derive the ranking based on their capability of reproducing historical climate, several statistical metrics were calculated as presented in the following. To compare datasets of the same length, the period 1989-2008 was chosen for the model selection. Model performance was evaluated on based on daily catchment precipitation derived from the common $0.11^{\circ}$ grid. Each of the statistical metrics was calculated for each reference dataset $r$, each climate model $c$, and each month $m$.

To assess the capability of the RCMs to reproduce the general climatology, the percent bias (PBIAS) was calculated defined as follows, where RCM refers to the evaluated RCM and Ref corresponds to the reference dataset used for the evaluation:

$$
\text { PBIAS }=\frac{1}{m} \sum_{m=1}^{12} \frac{\left(\overline{\operatorname{RCM}}_{c, m}-\overline{\operatorname{Ref}_{r, m}}\right)}{\overline{\operatorname{Ref}}_{r, m}} .
$$

The overall bias based on annual precipitation instead of monthly time steps was calculated in a similar way. To further assess the RCM performance, the root-meansquare error (RMSE) and the mean absolute error (MAE) were computed based on the entire ranked time series. In addition, to assess the performance of the upper end of the distribution, both metrics were computed for the 90th percentile as follows, and the 95th, 99th, and 99.9th percentiles were calculated the same way:

$$
\mathrm{MAE}=\frac{1}{m} \sum_{m=1}^{12}\left|P^{90}\left(\mathrm{RCM}_{c, m}\right)-P^{90}\left(\operatorname{Ref}_{r, m}\right)\right|, \quad \text { and }
$$

$$
\mathrm{RMSE}=\sqrt{\frac{1}{m} \sum_{m=1}^{12}\left[P^{90}\left(\mathrm{RCM}_{c, m}\right)-P^{90}\left(\operatorname{Ref}_{r, m}\right)\right]^{2}} .
$$

In addition, to assess the variability in the reference and RCM datasets, the interannual variability of both annual and monthly precipitation sums were calculated based on the standard deviations over the 20 -yr period.

For each of the metrics, and each of their variations (temporal or percentile based), a simple score system was applied to rank the models. In a first step, the resulting metrics were normalized individually so that the best performing model was awarded $100 \%$ and the other models decrease accordingly. In a second step, the average score in percent was calculated as the simple mean over the calculated metrics. A score of $100 \%$ thus does not mean the model performs perfectly but is rather the best-performing model relative to the rest of the RCM ensemble. This procedure might inflate the differences between the RCMs if the models show similar scores. To reduce the ensemble to a feasible 
number of simulations, the best three and seven ranking RCMs based on each of the reference datasets were selected for the analyses.

\section{b. Bias correction method}

As RCMs are usually prone to biases on the regional or local scale, bias correction is a necessary, though controversial, step (Muerth et al. 2013). Here a two-step correction was applied. First, to avoid artifacts in the RCM distributions, a simple threshold was introduced to correct the drizzle effect, which produces too many days with very low precipitation (Teutschbein and Seibert 2013). In a second step a distribution-based correction method based on the daily translation (DT) method (Mpelasoka and Chiew 2009; Chen et al. 2013b) was applied to correct RCM precipitation. DT is similar to other QM bias correction methods and showed effective correction (Chen et al. 2013b). In contrast to Mpelasoka and Chiew (2009), the bias correction does not include an additional downscaling in this study, as all datasets were remapped to the RCM grid previously. In DT a relation between the distribution of precipitation in the reference dataset and the historical RCM dataset is established. The resulting correction factors for each percentile are then applied to correct the historical and future simulations of RCM precipitation. In this study the multiplicative correction factors are derived on a monthly basis and for integer percentiles. The period 1989-2008 served to derive the monthly correction factors which were then applied to correct the RCM ensemble introduced for the historical period (1981-2010) and future period (2036-65). The bias correction procedure was applied to the entire RCM ensemble under RCP8.5 for each of the nine reference datasets.

\section{c. Variance decomposition}

Four main sources of uncertainty can be identified in the design of the study: model uncertainty originating from GCMs and corresponding uncertainty introduced through RCMs; scenario or radiative uncertainty, introduced through different radiative forcings, RCP4.5, and RCP8.5; and finally uncertainty introduced through postprocessing. The latter here is the key interest and is defined as the uncertainty introduced through the bias correction with different reference datasets. To quantify the relative contribution of each of the four sources to the overall uncertainty, the widely used approach of variance decomposition (Déqué et al. 2007, 2012) is applied. The method will be briefly introduced here; for a detailed presentation of the concept, refer to Déqué et al. (2007).

Within this, the variance in the climate response, that is, the climate change signal defined as the difference in precipitation for the future period (2036-65) and the reference period (1981-2010), is analyzed. As bias correction also affects the spread of the climate model ensemble, also the absolute projections for mean monthly precipitation as well as heavy ( 0.95 quantile, Q95) and extreme precipitation (0.99 quantile, Q99) are assessed regarding their variances. The total variance of the ensemble is given by the sum of each of the four sources of uncertainty, where $G$ is defined as the contribution from the GCMs, $R$ the variance within the RCMs, $S$ the scenario uncertainty, and $B$ the uncertainty attributed to bias correction with different reference datasets:

$$
V_{\text {tot }}=G+R+S+B .
$$

As neither of the sources of uncertainty appears solely the interaction terms of the four sources have to be considered making Eq. (4) more complex and more difficult to interpret:

$$
\begin{aligned}
V_{\mathrm{tot}}= & G+R+S+B+G R+G S+G B+R S+R B \\
& +S B+G R S+G R B+G S B+R S B+G R S B .
\end{aligned}
$$

The variance due to each source of uncertainty can hence be considered the sum of all interaction terms with the corresponding variable. The uncertainty due to bias correction can thus be defined as

$$
\begin{aligned}
V_{B}= & B+G B+R B+S B+G R B+G S B \\
& +R S B+G R S B .
\end{aligned}
$$

Uncertainties due to GCM $(G), \operatorname{RCM}(R)$, and RCP or scenario $(S)$ can be written accordingly. The assumption of the total variance being the sum of each uncertainty component as in Eqs. (4) and (5) is only valid for a complete matrix. The matrix is complete for scenarios, as all simulations are available under RCP4.5 and RCP8.5 and for bias correction, as the entire ensemble was bias corrected with each reference dataset. However, as presented in Table 2, not all GCM-RCM combinations are available, and the matrix must be artificially filled. Following the simple yet robust approach presented by Déqué et al. (2007) to solve this problem, the calculation of the climate responses was computed that the interaction term GRSB equals zero. Thus, the interaction terms are not correct by definition, however the goal of this study is to estimate the contribution of each source to the overall variance and not represent the interaction between them. The final variance hence also represents only the fraction of uncertainty of each source rather than the total variance. The interaction terms are therefore included in the final 


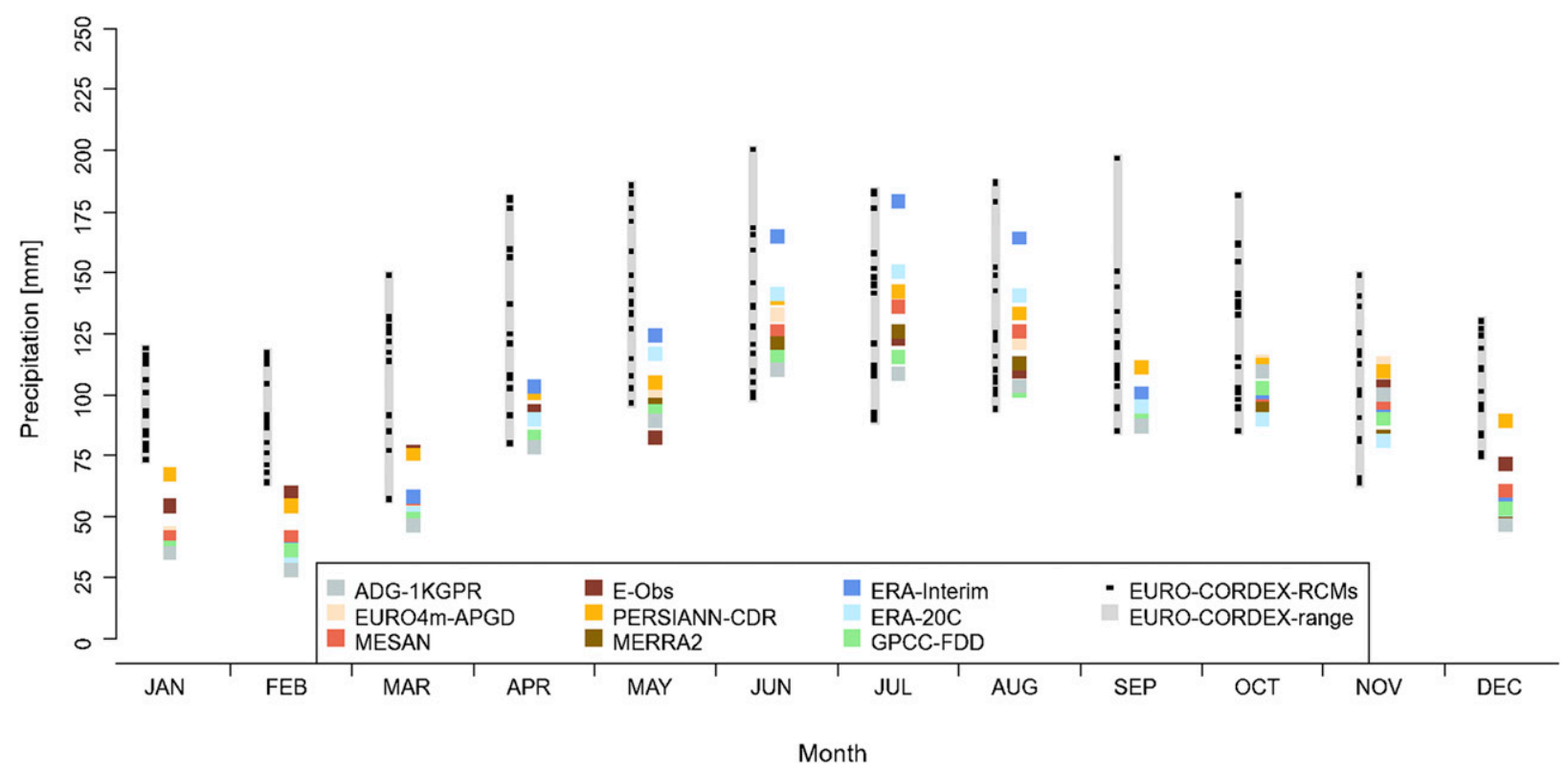

FIG. 2. Uncorrected climatological monthly precipitation from EURO-CORDEX RCMs (black squares), the corresponding spread (dark gray bars), and the selected reference datasets (colored squares) for the period 1989-2010.

variance presented here and not explicitly mentioned. The sum of the overall variance exceeds $100 \%$ due to these interaction terms; therefore, the final variance is normalized to 1 , or $100 \%$ respectively, to represent the fraction but allow for easier and more accessible comparison of the results. The variance decomposition was carried out based on mean monthly climate change signals, as well as absolute monthly and heavy (Q95) and extreme (Q99) precipitation based on daily values in this study.

\section{Results}

Figure 2 shows the mean monthly precipitation sums over the Adige catchment for the EURO-CORDEX ensemble (gray bars, single models shown as black squares) and the nine selected reference datasets (colored squares) for the period 1989-2008. In general, the RCMs show a wet bias for most months and the spread of the climate model ensemble exceeds the spread of the reference datasets. Additionally, the spread of both, $\mathrm{RCMs}$ and reference datasets, is larger during the summer period (JJA) compared to the winter months (DJF) due to convective and heavy precipitation events in JJA. The detection of a potential model bias is easier to interpret in DJF, where each member of the RCM ensemble shows higher precipitation compared to each reference dataset, except for PERSIANN-CDR in December. In JJA the situation is different and the detection of model bias is more complex. Compared to ERA-Interim (blue square), most of the RCMs show a dry bias, while compared to the high-resolution ADG-1KGPR (gray square), GPCC-FDD (green), and MERRA2 (dark brown) most of the included RCMs show a wet bias.

To assess the RCM bias, Fig. 3 shows the percent model bias based on mean annual precipitation for the years 1989-2008 for the RCM ensemble and the nine reference datasets, numbering refers to Table 1 . A positive bias, shown in blue coloring, indicates an overestimation while a negative bias (red coloring) refers to precipitation underestimation. Circles in the panels indicate a bias lower than the observational uncertainty. The latter was derived from the coefficient of variation (CV) which is calculated as the standard deviation normalized by the overall mean of the reference datasets and given in percent. In this case the $\mathrm{CV}$ of the reference datasets based on annual precipitation is around $10 \%$. The average bias shown refers to the mean bias of each RCM over the reference datasets. Depending on the reference dataset up to five RCMs (for PERSIANN-CDR, column 5) show biases within this range and can therefore not be considered as biased. As already indicated for monthly precipitation in Fig. 2, most RCMs show a positive bias also for annual precipitation compared to most reference datasets. However, PERSIANN-CDR (column 5) and ERA-Interim (column 7) indicate underestimations of up to $20 \%$ for the RACMO22E simulations, while other reference datasets indicate a small positive bias for this RCM. Consequently, the average bias is close to zero as the positive biases are balanced with the negative biases. 


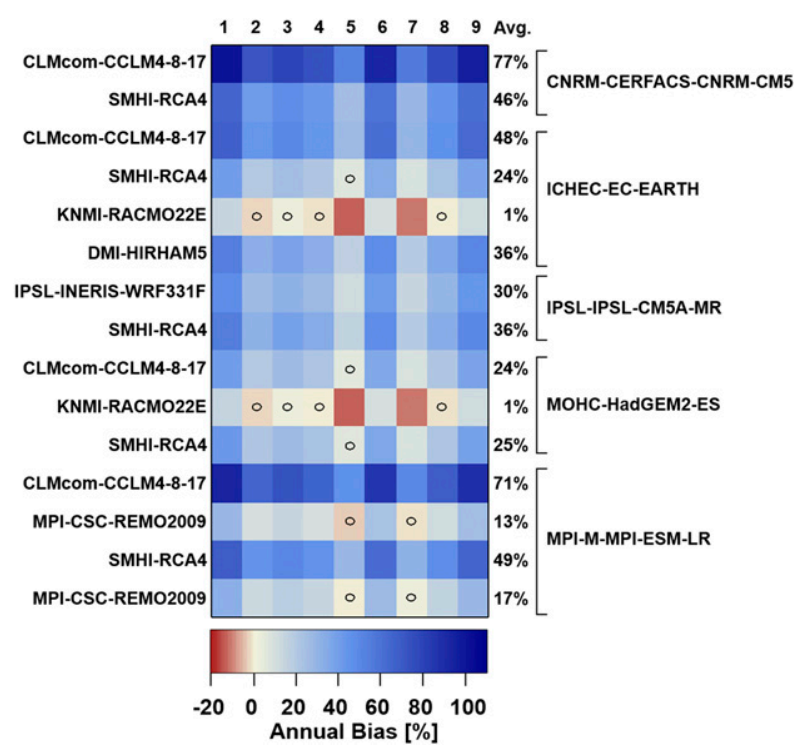

FIG. 3. Model bias for each RCM with respect to each reference dataset. Circles denote that the bias falls within the range of the observational uncertainty, which here is defined as the coefficient of variation of the climatological annual precipitation in the reference datasets $( \pm 10 \%)$.

In contrary, other RCMs, such as CCLM4-8-17 and RCA4, show positive biases throughout the reference datasets, independent from the driving GCM and show high average biases of up to $77 \%$.

This is also reflected in the average score for model selection as presented in Fig. 4 as RCMs with high annual bias show considerably lower scores. However, models with lower annual bias, for example, KNMI-RACMO22E driven by the HadGEM2-ES, do not necessarily score better than other models. The results additionally are more homogenous than the annual bias presented in Fig. 3. The least scoring RCMs show low performance throughout the reference datasets, while the best scoring RCMs are also similar for all reference datasets. Therefore, for many reference datasets the same models are among the selected three (filled circles in Fig. 4) or seven (nonfilled circles), respectively. The only reference dataset with considerable different scoring patterns is ERA-Interim, however the tendencies are similar. For each reference dataset, the best three and seven RCMs are selected for the subsequent analyses of future changes.

Figure 5 shows the percentiles of daily precipitation for the original (gray) and bias-corrected (red) RCM simulations with the corresponding reference products (Figs. 5a-i) used for bias correction. The positive bias detected in the climatological annual precipitation of the uncorrected RCMs (gray) can be clearly identified throughout the entire distribution for almost all

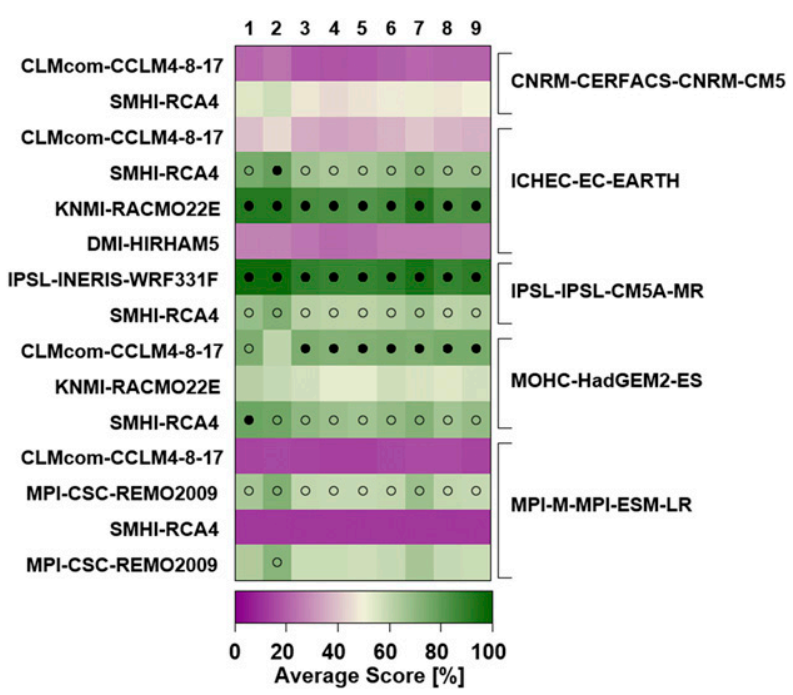

FIG. 4. Average score (\%) for each RCM and reference dataset. The average score is based on several metrics and normalized from $0 \%$ (worst RCM) to $100 \%$ (best RCM). Circles mark the three (filled) and seven (not filled) selected models with the highest score based on each reference dataset.

reference products compared to the corresponding reference dataset (black line). The corrected RCMs (red lines) agree better with each of the corresponding reference dataset. The remaining discrepancy can be attributed to different time horizons, as the reference datasets cover only the period 1989-2008, while the RCMs are presented for the entire reference period (1981-2010) in this figure. The correction of the drizzle effect led to a better representation of the lower end of the distribution, hence very little or no precipitation. As expected, bias correcting the RCM ensemble to observed percentiles results in a considerable reduction of the RCM spread over the historical period. The highest differences between the biascorrected RCM ensembles can be identified for low precipitation and the threshold of no-precipitation days, as well as the tail of the distribution characterizing extreme precipitation.

The best three and seven models evaluated against each of the reference datasets identified through the model selection process were selected from the corresponding bias-corrected RCM ensemble. Figure 6 shows the resulting monthly climate change signals for the selected three (seven) models as black spread and squares (colored bars), sorted by the reference dataset used for model selection and bias correction. The climate change signal here is defined as the percent change between the future period (2036-65) compared to the historical period (1981-2010). As similar models were selected for each of the reference datasets (Fig. 4), the spread of the 

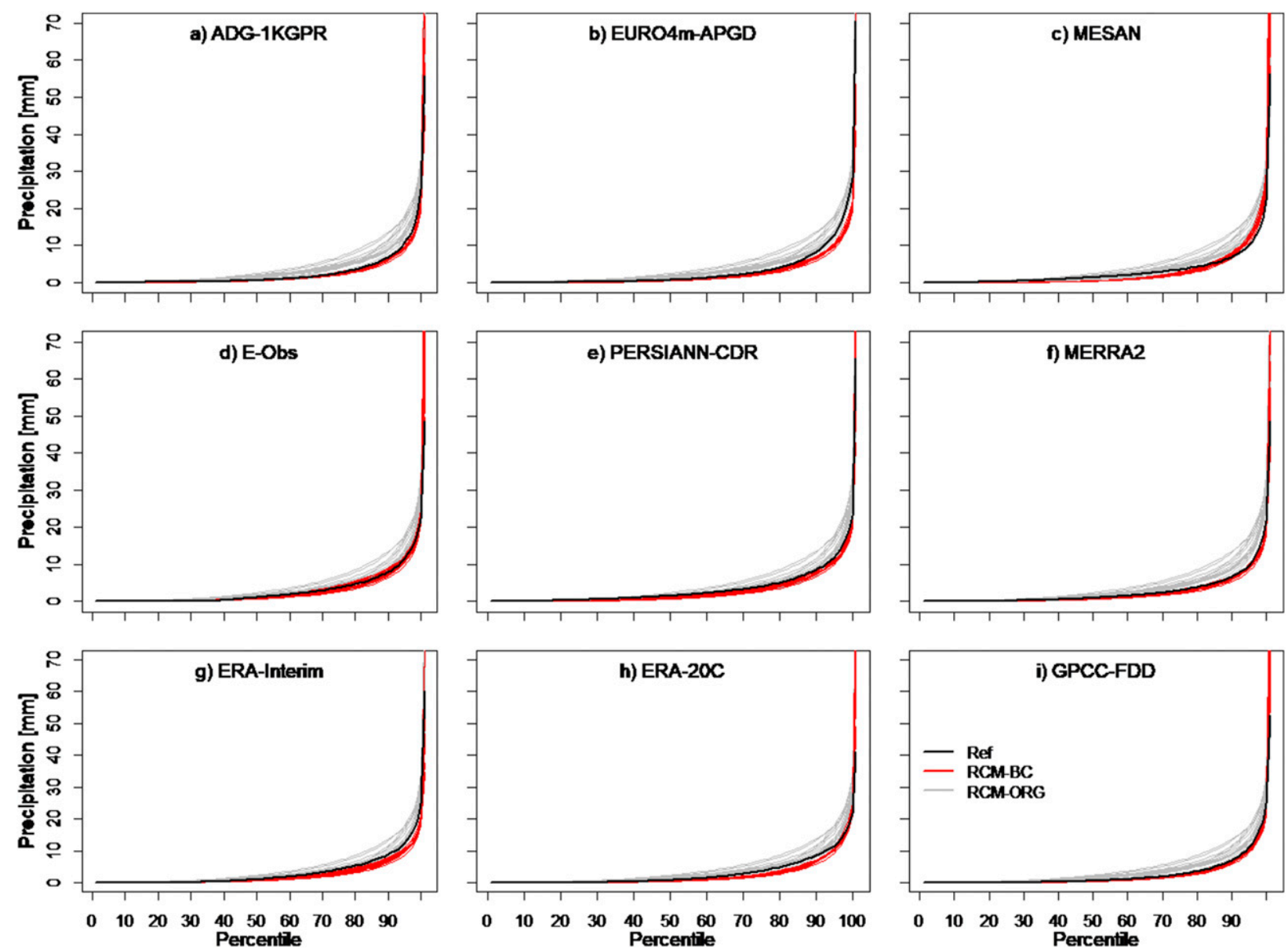

FIG. 5. (a)-(i) Percentiles of daily catchment precipitation for the selected reference datasets, the original EURO-CORDEX RCMs (gray lines), and the bias-corrected RCMs (red) for the period 1981-2010, while the reference datasets used for bias correction only cover the period 1989-2008.

projected change in precipitation is also alike, especially if seven models are selected. For the winter months, the selection of three models captures the spread of seven models while for the summer months the results are ambiguous. Due to the smaller number of selected models, the spread is smaller for only three selected models. Additionally, depending on the reference dataset, a selection of only three models leads to different signs in projected changes of precipitation. This results in positive changes for some reference datasets (August) while other datasets select a climate model that projects a decrease, such as for PERSIANN-CDR, MERRA2, and GPCC-FDD. Nevertheless, these differences are due to the model selection and not to bias correction, as the climate change signals are conserved throughout.

However, bias correction clearly changes the absolute values of projected precipitation. Figure 7 shows projected monthly precipitation for the future period (2036-65) for the selected three (seven) models as black spread and squares (colored bars), sorted by the reference dataset used for model selection and bias correction. Like Fig. 2, the model spread in the summer months is higher than for the winter period. As the reference datasets also agree more during the winter months (Fig. 2), projected changes in this period are more robust with respect to the reference dataset applied for bias correction. In summer, however, the impact of the reference dataset is stronger. The maximum precipitation projected for August thus varies between $120 \mathrm{~mm}$ (E-OBS) and $190 \mathrm{~mm}$ (ERA-Interim). As the spread is similar for all reference datasets, a higher maximum projection consequently means also higher projections for the minimum monthly precipitation. Bias correcting the percentiles leads to projections following the course of the reference datasets in the historical period: bias correction with products that show higher precipitation in the reference period (ERA-Interim, PERSIANNCDR) results in higher projections. Both the sequence of the datasets and similar differences to the historical 


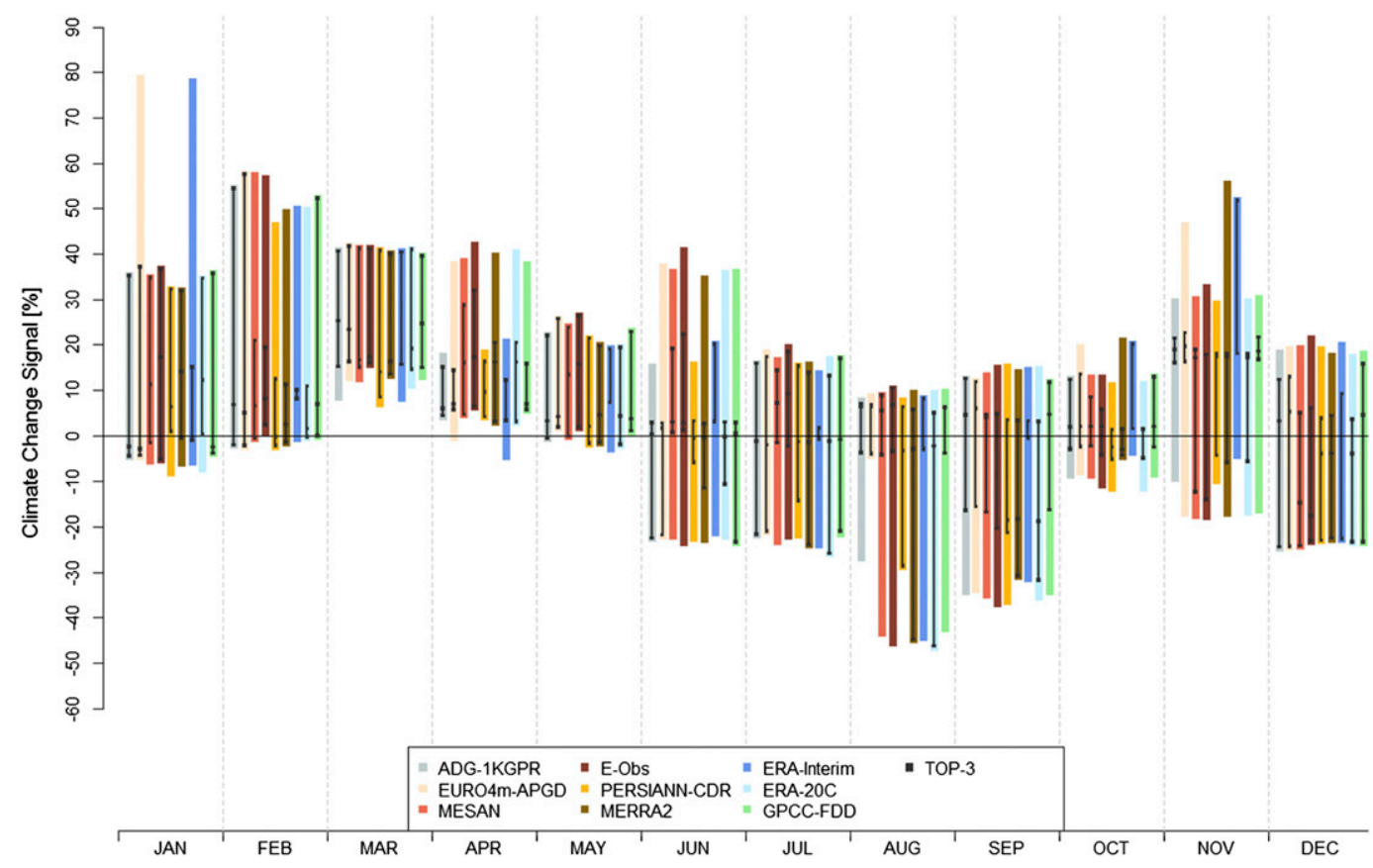

FIG. 6. Monthly projected spread of climate change signals for the selected best-fit seven (colored bars) or three (black lines and squares) bias-corrected RCMs. Coloring is according to the corresponding reference dataset applied for bias correction.

period are reproduced in the bias-corrected projections. The difference in August between E-OBS and ERAInterim in projected precipitation is thus similar to the reference datasets. As expected, the selection of only three models results in considerable differences in the projections. On the one hand this might lead to an extremely small spread (ERA-20C in February) or on the other hand to even more amplified differences in the projected monthly temperatures (ERAInterim and E-OBS in summer). As the model selection, however, is based on validity only, there is no systematic behavior and connection between model spread, absolute projected changes, and the reference product.

To assess the impact of bias correction with various reference datasets on projected heavy (extreme) precipitation, Fig. 8 shows the 0.95 (0.99) quantile of daily catchment precipitation. As for the previous figures, the selected three (seven) models are shown as black spread (colored bars), sorted by the reference dataset used for model selection and bias correction. For each reference dataset the left bar corresponds to the reference period and the right bar shows projected changes for the future horizon. Independent from the dataset used for bias correction, the RCMs agree in increased heavy and extreme precipitation. A general increase in heavy or extreme precipitation is projected by the RCM ensemble. As the climate change signal is maintained and independent from the applied reference dataset, the changes are also with a mean increase of $10 \%$. While the differences are not very distinct for the 95th percentile, the impact of the reference dataset is higher for extreme precipitation. As expected, bias correction with the high-resolution observational datasets (ADG-1KGPR and EURO4m-APGD) results in higher extreme precipitation. However, the impact of spatial resolution is smoothened as the assessment is based on catchment mean rather than gridcell based and all datasets were remapped in the preprocessing. The differences originating from the reference datasets are as high as $30 \%$ and exceed the projected changes indicating that observational uncertainty exceeds the climate change signal in case of extreme precipitation.

To assess the overall uncertainty of reference dataset selection on the climate change signal compared to model and scenario uncertainty, Fig. 9 shows the percentage of the total variance attributed to each source of uncertainty as result of the variance decomposition. As mentioned, these results reveal only the relative contribution to the total variance. The relative contribution of the RCM is show in dark blue, GCM in blue, RCP in light blue, and bias correction, here originating from different reference datasets only, in cyan. Figure 9a represents the composition of the variance of the climate change signal based on monthly precipitation data, Fig. $9 \mathrm{~b}$ shows the variances of projected absolute monthly 


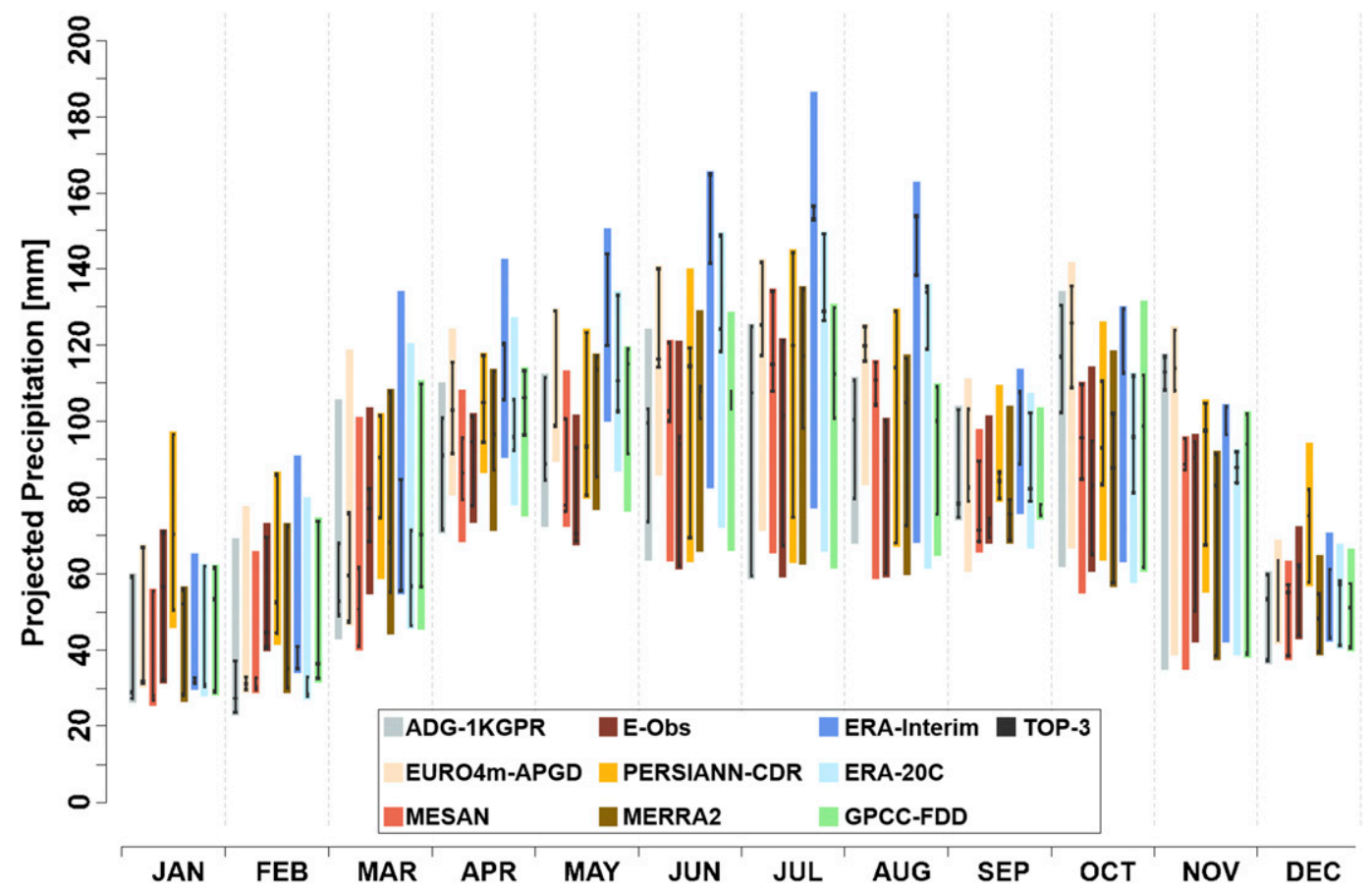

FIG. 7. Monthly projected spread of monthly precipitation for the selected best-fit seven (colored bars) or three (black lines and squares) bias-corrected RCMs for the period 2036-65. Coloring is according to the corresponding reference dataset applied for the bias correction.

precipitation projections, and Figs. 9c and 9d represent the projected Q95 and Q99, respectively. The uncertainty introduced by the GCMs is usually larger than the contribution of the RCMs for all months. GCM uncertainty contributes to $45 \%$ of the overall variance for the signal, while only $33 \%-35 \%$ for the absolute projections. As shown, the influence of bias correction with various datasets only slightly impacts the variance in the ensemble for the climate change signals, with only $9 \%$ (Fig. 9a). Due to the correction method at various quantiles, the composition of the variance for the climate change signal is preserved also for Q95 and Q99 and thus not shown here. However, for absolute projections the ensemble, as the ensemble spread changes, bias correction contributes with $40 \%-44 \%$ to the overall variance. The impact of bias correction on the total variance increases slightly for heavy and extreme precipitation.

\section{Discussion}

The presented results demonstrate the importance of reference dataset selection for climate model evaluation as the direction of bias (over- or underestimation of precipitation) is largely dependent on the reference dataset used for evaluation. The strongest differences are identified for ERA-Interim and PERSIANN-CDR, which already show strong differences to the rest of the ensemble in a previous study (Gampe and Ludwig 2017). This confirms the conclusions drawn in previous studies (Prein and Gobiet 2017; Kotlarski et al. 2017) also on the catchment scale. However, it is important to consider existing limitations in observational datasets such as undercatch (Rasmussen et al. 2012), interpolation errors (Addor and Fischer 2015), and station density (Isotta et al. 2015). It is clear and well established that low-resolution datasets cannot fully capture alpine precipitation and it should thus be avoided to apply these datasets for bias correction if higher-resolution datasets are available. As this might not be the case for all regions, these datasets are still applied in, for example, hydrological modeling (e.g., Poméon et al. 2018). Thus, they are nevertheless included in this study. The presented results highlight that the impact of coarse reference datasets increases for heavy precipitation. There is still a need for robust high-resolution datasets over larger domains for a better evaluation.

It is important to highlight here, that both the RCMs as also the reference datasets represent ensembles of opportunity and most of the datasets used in this study are not fully independent from each other. In case of the reference datasets they either partly use the same precipitation gauges for interpolation (all observational products + PERSIANN-CDR) or 


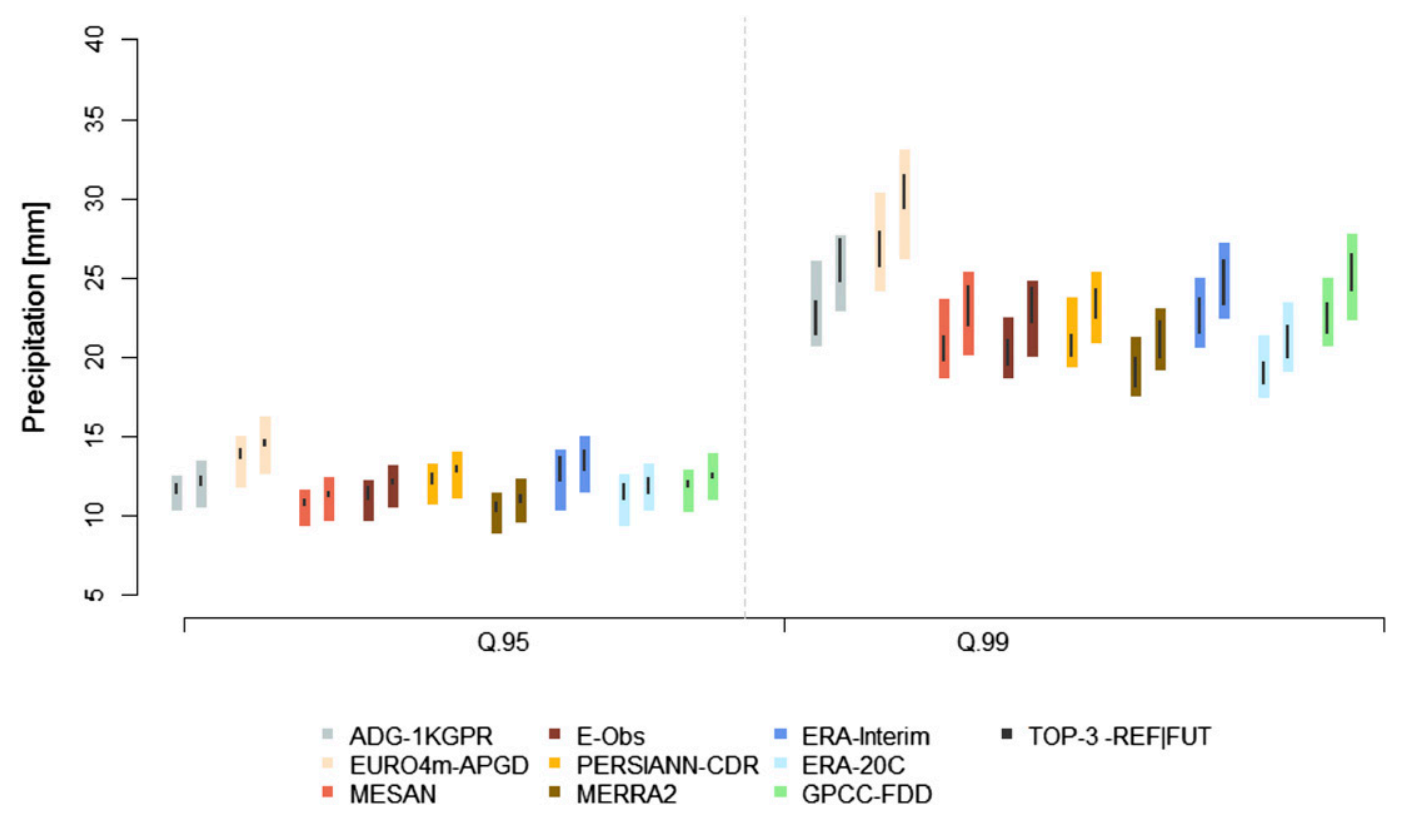

FIG. 8. Catchment (left) daily heavy (95th quantile) and (right) extreme precipitation (99th quantile) for the seven (colored bars) and three (black bars) selected RCMs for the reference period (left bar) and future projections (right bar). Coloring refers to the corresponding reference dataset.

assimilate this information in some (reanalysis products) or serve as boundary conditions for a higher-resolution data product (ERA-Interim and MESAN). However, this is a common problem when comparing different gridded precipitation products, which cannot be avoided. For the climate models the RCMs are often forced by the same GCM, however, the matrix is incomplete and similar schemes are implemented throughout the models. Additionally, the 20-yr time period for this analysis is relatively short, and additional uncertainties due to natural variability are not included in this study. Nevertheless, the general findings of this study will likely remain and the restricting lengths in available dataset are a common problem. However, a bootstrapping method could be applied to simulate and account for natural variability in future studies like Addor and Fischer (2015).

Despite the differences in the reference products, the RCMs score similarly for all reference datasets, again except for ERA-Interim. However, this is not negligible as depending on the number of models selected this will result in a different ensemble of RCMs chosen. The findings confirm the results presented by Kotlarski et al. (2017), who also applied a simple yet different scoring system. The similar scoring behavior of individual RCMs indicates again that model uncertainty exceeds observational uncertainty. Nevertheless, this also confirms the limitations of RCMs on the regional scale where fundamental difference arises, and the climatology and variability are not correctly reflected over a given area for a given model. This emphasizes the need to account for plausible RCM inputs for bias correction as proposed by Maraun (2016). Different validity-based selection can lead to partly severe changes in projections, especially if only a small subset of RCMs is selected, as presented in Fig. 4. The impact of model selection, although strongly dependent on the number of models selected, is thus considerable. Although QM also has an impact on the climate change signal (Maraun 2016), the differences in the presented signals largely originate from the selection process. This confirms the findings of Dosio et al. (2012) that the influence of bias correction is only small on projected change signals for mean precipitation and expected as the same correction factors are applied for both periods. This agrees with the findings presented in previous studies and can be attributed to different corrections of the quantiles and underlying trends in the data (Themeß1 et al. 2012).

However, bias correction with different reference products has severe impacts on absolute projected precipitation. The bias-corrected RCM ensemble represents the features found for the reference dataset, as wetter reference datasets consequently introduce wetter projections. This effect becomes even more severe for extreme precipitation. The findings in this study, as in Iizumi et al. (2017), show that the uncertainty originating from the reference dataset exceeds the uncertainty from the climate model projections for bias-corrected 
a) Signal, Mean

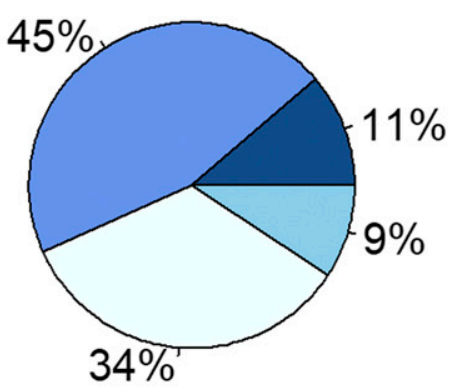

b) Mean

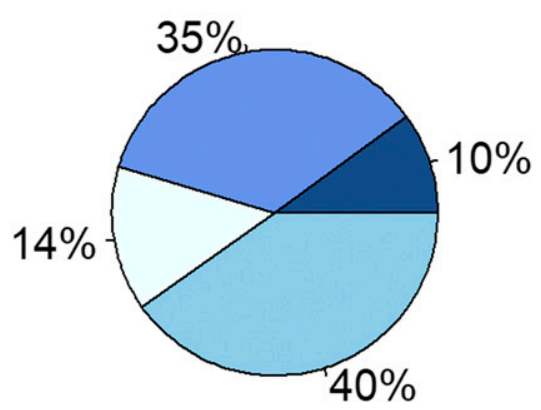

c) Q95

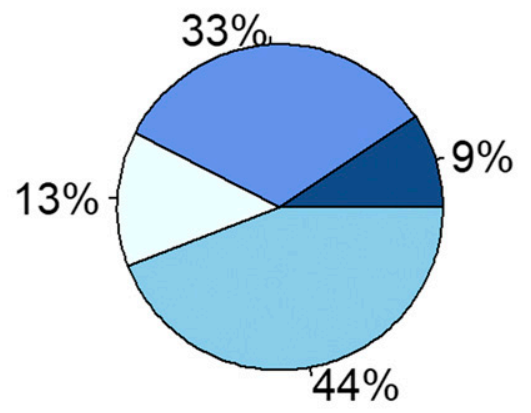

d) Q99

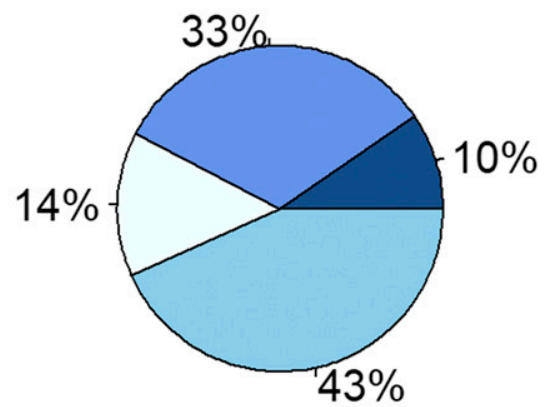

\section{$\square \mathrm{RCM} \square \mathrm{GCM} \square \mathrm{RCP} \square \mathrm{BC}$}

FIG. 9. Relative contribution of RCM (dark blue), GCM (blue), RCP (light blue), and bias correction (cyan) for (a) monthly climate change signals, (b) projected absolute changes in mean monthly precipitation, and projected absolute changes in (c) heavy (Q95) and (d) extreme precipitation (Q99) to the overall variance.

extremes. As presented, for absolute precipitation the contribution to the overall variance is also inflated. This is highly relevant for future studies focusing on extreme events and projections of changes in these. It should be noted that the presented results in this study focus on the magnitude of precipitation only. Other important characteristics, such as sequencing of precipitation events, are not considered. Due to nonlinear responses from, for example, hydrological models on different precipitation datasets, the resulting uncertainties thus cannot be transferred directly. The results presented by Teng et al. (2015) reveal that uncertainties in simulated runoff are considerably larger than the raw bias of RCMs, suggesting that the related uncertainty of bias correction is likely altered for impact modeling.

The contribution to the overall variance was assessed for each uncertainty source through a variance decomposition approach. As in previous studies (Déqué et al.
2007; Gampe et al. 2016), the contribution of the GCM dominates the uncertainty, followed by RCP and RCM. However, as uncertainty originating from the choice of the RCP cannot be considered a random error, the uncertainty for this component might be underrepresented by the presented method. Bias correction uncertainty only contributes around $9 \%$ to the overall variance. For absolute projections, however, this becomes the main source of uncertainty with $40 \%-44 \%$, increasing for the extremes, thus exceeding GCM uncertainty.

\section{Conclusions}

This exploratory study highlights the importance to consider multiple reference datasets for bias correction to derive more robust results in climate change impact assessment studies. Observational uncertainty, that is, uncertainty originating from various reference datasets, 
is still widely ignored in climate change impact studies, especially when it comes to bias correction of RCMs. This study addresses the impacts of reference dataset selection on climate model evaluation, model selection, bias correction, and resulting climate change signals for an alpine catchment.

The presented results indicate that observational uncertainty has only a small impact on model selection for a validity-based selection procedure. This suggests that RCM bias generally exceeds observational uncertainty, at least for the applied metrics. This is also reflected in the assessment of annual RCM biases, as the reference datasets mostly agree in the direction of the bias. However, for better-performing RCMs, that is, those with relatively low biases, the detection and direction of model bias differs. Consequently, observational uncertainty is this thus crucial for the detection and correction of model biases for those RCMs.

As expected, due to the methodology applied (QM using monthly correction factors), bias correction barely impacts the resulting climate change signals. However, bias correction severely changes the absolute values of precipitation and thus imports the characteristics of the reference datasets directly to the RCM data. This becomes more pronounced for heavy (Q95) and extreme (Q99) precipitation. Observational uncertainty thus plays a major role, especially for studies focusing on projections of future extremes, for example, through hydrological modeling, where through the nonlinearity in the responses the effect is likely amplified.

The contribution of reference dataset uncertainty in the presented framework to the overall uncertainty of the climate change signal is assessed by a variance decomposition approach. Four main sources of uncertainty were included in the analysis: model uncertainty originating from GCM and RCM, scenario uncertainty from the RCP, and bias correction uncertainty through different reference datasets. The large contribution of GCMs to the relative variance should be considered in the model selection process. If the motivation is to capture the spread of GCM-RCM projections, a larger number of GCMs should be preferred. Although observational uncertainty is generally smaller than RCM-related uncertainty, it can be of similar magnitude, especially when the precipitation systems get more complex, for example, through convective systems in summer. For absolute projections however, the selection of the dataset becomes crucial as it contributes $40 \%-44 \%$ to the overall uncertainty and thus exceeds also the share of the GCM. This finding clearly highlights the potential influence of observational uncertainty and the application of bias-corrected datasets for climate change impact assessment studies.
Overall, this study confirms the outlooks by Prein and Gobiet (2017) and Kotlarski et al. (2017) and highlights the need to account for observational uncertainty when bias correction is applied to climate model data. As the quality of the bias correction procedure is strongly dependent on the selected reference dataset, the selection of these should be based on thorough investigation of available datasets instead of arbitrary selection. Due to these impacts on the quality of the bias correction procedure, there is still a need for accurate observations and high-resolution reference datasets for better corrections and more transparent results in future studies.

Nevertheless, the presented study focuses only on one catchment and results may not be transferable to other areas and regions. The presented catchment can be considered as especially challenging due to the complex topography and high altitudes with lower station density. As this hinders the interpretation of the results of this study, future work on other catchments and regions needs to be carried out to confirm the magnitude of reference uncertainty on bias correction. Due to the mentioned nonlinearity in the responses of, for example, hydrological models, future studies must be carried out to evaluate the effect and consequences of observational uncertainty and bias correction for climate change impact assessment studies potentially with a focus on extremes.

Acknowledgments. This work has been supported by the European Communities 7th Framework Programme Funding under Grant Agreement 603629-ENV-20136.2.1-Globaqua.

\section{REFERENCES}

Addor, N., and E. M. Fischer, 2015: The influence of natural variability and interpolation errors on bias characterization in RCM simulations. J. Geophys. Res. Atmos., 120, 10180 10 195, https://doi.org/10.1002/2014JD022824.

— M. Rohrer, R. Furrer, and J. Seibert, 2016: Propagation of biases in climate models from the synoptic to the regional scale: Implications for bias adjustment. J. Geophys. Res. Atmos. 121, 2075-2089, https://doi.org/10.1002/2015JD024040.

Ashouri, H., K. L. Hsu, S. Sorooshian, D. K. Braithwaite, K. R. Knapp, L. D. Cecil, B. R. Nelson, and O. P. Prat, 2015: PERSIANN-CDR: Daily precipitation climate data record from multisatellite observations for hydrological and climate studies. Bull. Amer. Meteor. Soc., 96, 69-83, https://doi.org/ 10.1175/BAMS-D-13-00068.1.

Biemans, H., L. H. Speelman, F. Ludwig, E. J. Moors, A. J. Wiltshire, P. Kumar, D. Gerten, and P. Kabat, 2013: Future water resources for food production in five South Asian river basins and potential for adaptation - a modeling study. Sci. Total Environ., 468-469, S117-S131, https://doi.org/10.1016/ j.scitotenv.2013.05.092.

Bosilovich, M. G., R. Lucchesi, and M. Suarez, 2016: MERRA-2: File specification. GMAO Office Note 9 (version 1.1), 73 pp., https://gmao.gsfc.nasa.gov/pubs/docs/Bosilovich785.pdf. 
Chen, J., F. P. Brissette, D. Chaumont, and M. Braun, 2013a: Finding appropriate bias correction methods in downscaling precipitation for hydrologic impact studies over North America. Water Resour. Res., 49, 4187-4205, https://doi.org/ 10.1002/wrcr.20331.

,,,--- and,$- 2013 \mathrm{~b}$ : Performance and uncertainty evaluation of empirical downscaling methods in quantifying the climate change impacts on hydrology over two North American river basins. J. Hydrol., 479, 200-214, https:// doi.org/10.1016/j.jhydrol.2012.11.062.

Chiogna, G., B. Majone, K. C. Paoli, E. Diamantini, E. Stella, S. Mallucci, V. Lencioni, F. Zandonai, and A. Bellin, 2016: A review of hydrological and chemical stressors in the Adige catchment and its ecological status. Sci. Total Environ., 540, 429-443, https://doi.org/10.1016/j.scitotenv.2015.06.149.

Christensen, J. H., F. Boberg, O. B. Christensen, and P. LucasPicher, 2008: On the need for bias correction of regional climate change projections of temperature and precipitation. Geophys. Res. Lett., 35, L20709, https://doi.org/10.1029/2008GL035694.

Compo, G. P., and Coauthors, 2011: The Twentieth Century Reanalysis Project. Quart. J. Roy. Meteor. Soc., 137, 1-28, https:// doi.org/10.1002/qj.776.

Dahlgren, P., T. Landelius, P. Kållberg, and S. Gollvik, 2016: A highresolution regional reanalysis for Europe. Part 1: Threedimensional reanalysis with the regional HIgh-Resolution Limited-Area Model (HIRLAM). Quart. J. Roy. Meteor. Soc., 142, 2119-2131, https://doi.org/10.1002/qj.2807.

Dee, D. P., and Coauthors, 2011: The ERA-Interim reanalysis: Configuration and performance of the data assimilation system. Quart. J. Roy. Meteor. Soc., 137, 553-597, https://doi.org/10.1002/qj.828.

Déqué, M., and Coauthors, 2007: An intercomparison of regional climate simulations for Europe: Assessing uncertainties in model projections. Climatic Change, 81, 53-70, https://doi.org/ 10.1007/s10584-006-9228-x.

Déqué, G. P., S. Somot, E. Sanchez-Gomez, C. M. Goodess, D. Jacob, G. Lenderink, and O. B. Christensen, 2012: The spread amongst ENSEMBLES regional scenarios: Regional climate models, driving general circulation models and interannual variability. Climate Dyn., 38, 951-964, https://doi.org/10.1007/s00382-011-1053-x.

Dosio, A., 2016: Projections of climate change indices of temperature and precipitation from an ensemble of bias-adjusted high-resolution EURO-CORDEX regional climate models. J. Geophys. Res. Atmos., 121, 5488-5511, https://doi.org/10.1002/ 2015JD024411.

__ P. Paruolo, and R. Rojas, 2012: Bias correction of the ENSEMBLES high resolution climate change projections for use by impact models: Analysis of the climate change signal. J. Geophys. Res., 117, D17110, https://doi.org/10.1029/ 2012JD017968.

Ehret, U., V. Wulfmeyer, K. Warrach-Sagi, and J. Liebert, 2012: Should we apply bias correction to global and regional climate model data? Hydrol. Earth Syst. Sci., 16, 3391-3404, https:// doi.org/10.5194/hess-16-3391-2012.

Evans, J. P., F. Ji, C. Lee, P. Smith, D. Argüeso, and L. Fita, 2014: Design of a regional climate modelling projection ensemble experiment - NARCliM. Geosci. Model Dev., 7, 621-629, https://doi.org/10.5194/gmd-7-621-2014.

Frei, C., and C. Schär, 1998: A precipitation climatology of the Alps from high-resolution rain-gauge observations. Int. J. Climatol., 18, 873-900, https://doi.org/10.1002/(SICI)1097-0088(19980630) 18:8<873::AID-JOC255>3.0.CO;2-9.

Gampe, D., and R. Ludwig, 2017: Evaluation of gridded precipitation data products for hydrological applications in complex topography. Hydrology, 4, 53, https://doi.org/10.3390/ hydrology 4040053 .

, G. Nikulin, and R. Ludwig, 2016: Using an ensemble of regional climate models to assess climate change impacts on water scarcity in European river basins. Sci. Total Environ., 573, 15031518, https://doi.org/10.1016/j.scitotenv.2016.08.053.

Haylock, M. R., N. Hofstra, A. M. G. Klein Tank, E. J. Klok, P. D. Jones, and M. New, 2008: A European daily high-resolution gridded data set of surface temperature and precipitation for 1950-2006. J. Geophys. Res., 113, D20119, https://doi.org/ 10.1029/2008JD010201.

Henn, B., A. J. Newman, B. Livneh, C. Daly, and J. D. Lundquist, 2018: An assessment of differences in gridded precipitation datasets in complex terrain. J. Hydrol., 556, 1205-1219, https:// doi.org/10.1016/j.jhydrol.2017.03.008.

Herold, N., A. Behrangi, and L. V. Alexander, 2017: Large uncertainties in observed daily precipitation extremes over land. J. Geophys. Res. Atmos., 122, 668-681, https://doi.org/10.1002/ 2016JD025842.

Hersbach, H., C. Peubey, A. Simmons, P. Berrisford, P. Poli, and D. Dee, 2015: ERA-20CM: A twentieth-century atmospheric model ensemble. Quart. J. Roy. Meteor. Soc., 141, 2350-2375, https://doi.org/10.1002/qj.2528.

Hsu, K. L., X. Gao, S. Sorooshian, and H. V. Gupta, 1997: Precipitation estimation from remotely sensed information using artificial neural networks. J. Appl. Meteor., 36, 1176-1190, https:// doi.org/10.1175/1520-0450(1997)036<1176:PEFRSI >2.0.CO;2.

Iizumi, T., H. Takikawa, Y. Hirabayashi, N. Hanasaki, and M. Nishimori, 2017: Contributions of different bias-correction methods and reference meteorological forcing data sets to uncertainty in projected temperature and precipitation extremes. J. Geophys. Res. Atmos., 122, 7800-7819, https:// doi.org/10.1002/2017JD026613.

Isotta, F. A., and Coauthors, 2014: The climate of daily precipitation in the Alps: development and analysis of a highresolution grid dataset from pan-Alpine rain-gauge data. Int. J. Climatol., 34, 1657-1675, https://doi.org/10.1002/joc.3794.

, R. Vogel, and C. Frei, 2015: Evaluation of European regional reanalyses and downscalings for precipitation in the Alpine region. Meteor. Z., 24, 15-37, https://doi.org/10.1127/metz/ 2014/0584.

Jacob, D., and Coauthors, 2014: EURO-CORDEX: New highresolution climate change projections for European impact research. Reg. Environ. Change, 14, 563-578, https://doi.org/ 10.1007/s10113-013-0499-2.

Kotlarski, S., and Coauthors, 2017: Observational uncertainty and regional climate model evaluation: A pan-European perspective. Int. J. Climatol., https://doi.org/10.1002/joc.5249.

Kummerow, C., W. Barnes, T. Kozu, J. Shiue, and J. Simpson, 1998: The Tropical Rainfall Measuring Mission (TRMM) sensor package.J. Atmos. Oceanic Technol., 15, 809-817, https://doi.org/ 10.1175/1520-0426(1998)015<0809:TTRMMT>2.0.CO;2.

Lafon, T., S. Dadson, G. Buys, and C. Prudhomme, 2013: Bias correction of daily precipitation simulated by a regional climate model: A comparison of methods. Int. J. Climatol., 33, 1367-1381, https://doi.org/10.1002/joc.3518.

Landelius, T., P. Dahlgren, S. Gollvik, A. Jansson, and E. Olsson, 2016: A high-resolution regional reanalysis for Europe. Part 2: 2D analysis of surface temperature, precipitation and wind. Quart. J. Roy. Meteor. Soc., 142, 2132-2142, https://doi.org/ 10.1002/qj.2813.

Lutz, A. F., H. W. ter Maat, H. Biemans, A. B. Shrestha, P. Wester, and W. W. Immerzeel, 2016: Selecting representative climate 
models for climate change impact studies: an advanced envelope-based selection approach. Int. J. Climatol., 36, 3988-4005, https://doi.org/10.1002/joc.4608.

Maraun, D., 2016: Bias correcting climate change simulations - A critical review. Curr. Climate Change Rep., 2, 211-220, https:// doi.org/10.1007/s40641-016-0050-x.

Mendlik, T., and A. Gobiet, 2016: Selecting climate simulations for impact studies based on multivariate patterns of climate change. Climatic Change, 135, 381-393, https://doi.org/10.1007/s10584015-1582-0.

Mpelasoka, F. S., and F. H. S. Chiew, 2009: Influence of rainfall scenario construction methods on runoff projections. J. Hydrometeor., 10, 1168-1183, https://doi.org/10.1175/ 2009JHM1045.1.

Muerth, M., and Coauthors, 2013: On the need for bias correction in regional climate scenarios to assess climate change impacts on river runoff. Hydrol. Earth Syst. Sci., 17, 1189-1204, https:// doi.org/10.5194/hess-17-1189-2013.

Navarro-Ortega, A., and Coauthors, 2015: Managing the effects of multiple stressors on aquatic ecosystems under water scarcity. The GLOBAQUA project. Sci. Total Environ., 503-504, 3-9, https://doi.org/10.1016/j.scitotenv.2014.06.081.

Palazzi, E., J. Hardenberg, and A. Provenzale, 2013: Precipitation in the Hindu-Kush Karakoram Himalaya: Observations and future scenarios. J. Geophys. Res. Atmos., 118, 85-100, https:// doi.org/10.1029/2012JD018697.

Piani, C., J. O. Haerter, and E. Coppola, 2010: Statistical bias correction for daily precipitation in regional climate models over Europe. Theor. Appl. Climatol., 99, 187-192, https:// doi.org/10.1007/s00704-009-0134-9.

Pierce, D. W., T. P. Barnett, B. D. Santer, and P. J. Gleckler, 2009: Selecting global climate models for regional climate change studies. Proc. Natl. Acad. Sci. USA, 106, 8441-8446, https://doi.org/ 10.1073/pnas.0900094106.

, D. R. Cayan, E. P. Maurer, J. T. Abatzoglou, and K. C. Hegewisch, 2015: Improved bias correction techniques for hydrological simulations of climate change. J. Hydrometeor., 16, 2421-2442, https://doi.org/10.1175/JHM-D-14-0236.1.

Poli, P., and Coauthors, 2016: ERA-20C: An atmospheric reanalysis of the twentieth century. J. Climate, 29, 4083-4097, https://doi.org/10.1175/JCLI-D-15-0556.1.

Poméon, T., B. Diekkrüger, and R. Kumar, 2018: Computationally efficient multivariate calibration and validation of a grid-based hydrologic model in sparsely gauged West African river basins. Water, 10, 1418, https://doi.org/10.3390/w10101418.

Prein, A. F., and A. Gobiet, 2017: Impacts of uncertainties in European gridded precipitation observations on regional climate analysis. Int. J. Climatol., 37, 305-327, https://doi.org/ 10.1002/joc. 4706 .

— , and Coauthors, 2016: Precipitation in the EURO-CORDEX $0.11^{\circ}$ and $0.44^{\circ}$ simulations: High resolution, high benefits? Climate Dyn., 46, 383-412, https://doi.org/10.1007/s00382-0152589-y.

Rajczak, J., S. Kotlarski, N. Salzmann, and C. Schär, 2016: Robust climate scenarios for sites with sparse observations: A twostep bias correction approach. Int. J. Climatol., 36, 1226-1243, https://doi.org/10.1002/joc.4417.

Rasmussen, R., and Coauthors, 2012: How well are we measuring snow: The NOAA/FAA/NCAR winter precipitation test bed.
Bull. Amer. Meteor. Soc., 93, 811-829, https://doi.org/10.1175/ BAMS-D-11-00052.1.

Ruiz-Ramos, M., A. Rodríguez, A. Dosio, C. M. Goodess, C. Harpham, M. I. Mínguez, and E. Sánchez, 2016: Comparing correction methods of RCM outputs for improving crop impact projections in the Iberian Peninsula for 21st century. Climatic Change, 134, 283-297, https://doi.org/10.1007/s10584015-1518-8.

Schaller, N., I. Mahlstein, J. Cermak, and R. Knutti, 2011: Analyzing precipitation projections: A comparison of different approaches to climate model evaluation. J. Geophys. Res., 116, D10118, https://doi.org/10.1029/2010JD014963.

Schamm, K., M. Ziese, K. Raykova, A. Becker, P. Finger, A. Meyer-Christoffer, and U. Schneider, 2016: GPCC Full Data Daily version 1.0: daily land-surface precipitation from rain gauges built on GTS based and historic data. NCAR RDA, accessed 29 December 2017, https://doi.org/10.5065/ D6V69GRT.

Smiatek, G., H. Kunstmann, and A. Senatore, 2016: EUROCORDEX regional climate model analysis for the Greater Alpine Region: Performance and expected future change. J. Geophys. Res. Atmos., 121, 7710-7728, https://doi.org/ 10.1002/2015JD024727.

Teng, J., N. J. Potter, F. H. S. Chiew, L. Zhang, B. Wang, J. Vaze, and J. P. Evans, 2015: How does bias correction of regional climate model precipitation affect modelled runoff? Hydrol. Earth Syst. Sci., 19, 711-728, https://doi.org/10.5194/hess-19711-2015.

Teutschbein, C., and J. Seibert, 2013: Is bias correction of regional climate model (RCM) simulations possible for non-stationary conditions? Hydrol. Earth Syst. Sci., 17, 5061, https://doi.org/ 10.5194/hess-17-5061-2013.

Themeß1, M. J., A. Gobiet, and A. Leuprecht, 2011: Empiricalstatistical downscaling and error correction of daily precipitation from regional climate models. Int. J. Climatol., $\mathbf{3 1}$ 1530-1544, https://doi.org/10.1002/joc.2168.

, _ _ and G. Heinrich, 2012: Empirical-statistical downscaling and error correction of regional climate models and its impact on the climate change signal. Climatic Change, 112, 449-468, https://doi.org/10.1007/s10584-011-0224-4.

Torma, C., F. Giorgi, and E. Coppola, 2015: Added value of regional climate modeling over areas characterized by complex terrain-Precipitation over the Alps. J. Geophys. Res. Atmos., 120, 3957-3972, https://doi.org/10.1002/2014JD022781.

Van Vuuren, D. P., and Coauthors, 2011: The representative concentration pathways: an overview. Climatic Change, 109, 5 , https://doi.org/10.1007/s10584-011-0148-z.

Volosciuk, C., D. Maraun, M. Vrac, and M. Widmann, 2017: A combined statistical bias correction and stochastic downscaling method for precipitation. Hydrol. Earth Syst. Sci., 21, 1693-1719, https://doi.org/10.5194/hess-21-1693-2017.

Wilcke, R., and L. Bärring, 2016: Selecting regional climate scenarios for impact modelling studies. Environ. Modell. Software, $\mathbf{7 8}$, 191-201, https://doi.org/10.1016/j.envsoft.2016.01.002.

Zubler, E. M., A. M. Fischer, F. Fröb, and M. A. Liniger, 2016: Climate change signals of CMIP5 general circulation models over the Alps-Impact of model selection. Int. J. Climatol., 36 3088-3104, https://doi.org/10.1002/joc.4538. 